\title{
A novel form of syndromic cutis laxa with facial dysmorphism, cleft palate, and mental retardation
}

\author{
D Genevieve, C Baumann, C Huber, L Faivre, D Sanlaville, C Bodemer, S Hadj-Rabia, \\ A Assoumou, A Verloes, F Raqbi, A Munnich, V Cormier-Daire
}

J Med Genet 2004;41:e77 (http://www.jmedgenet.com/cgi/content/full/41/6/e77). doi: 10.1136/jmg.2003.013573

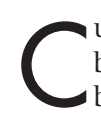
utis laxa (CL) is a rare congenital disorder characterised by loose and redundant skin. Three groups of CL have been recognised, according to their mode of inheritance. The first group, accepted as an autosomal dominant trait, is relatively benign, with late onset skin manifestations and subnormal life span. Other manifestations occasionally include pulmonary artery stenosis, emphysema, bronchiectasis, hernia, and genital prolapse. ${ }^{1}$ This subtype is ascribed to mutations in the elastin gene. ${ }^{2}$ The second group (also called Ehlers-Danlos type IX syndrome or mild Menkes syndrome) undergoes an X-linked recessive inheritance and has been ascribed to ATP7A deficiency. ${ }^{4}$ The third group, inherited as an autosomal recessive (AR) trait, includes type I and type II CL, wrinkly skin syndrome, and De Barsy syndrome. Type I AR CL is characterised by early infantile pulmonary emphysema, hernias, multiple diverticulae, and a poor prognosis. ${ }^{5}$ Recently, fibulin 5 mutations have been reported in Turkish patients with CL AR type I and supravalvular aortic stenosis. ${ }^{6}$ Type II AR CL is associated with growth and developmental delay, joint laxity, peculiar face with frontal bossing, large fontanelle, and skeletal dysplasia including congenital dislocations of the hips..$^{7-9}$ A deficiency in lysyl oxydase has been suggested in CL AR type $\mathrm{II}^{10}{ }^{10}$ which is closely related to wrinkly skin syndrome. ${ }^{11}$ Finally, De Barsy ${ }^{12}$ syndrome is associated with mental retardation, short stature, and corneal clouding. Here, we report on a novel type of AR CL with facial dysmorphism, hygroma in early pregnancy, cleft hard palate, ventricular septal defect, and moderate mental retardation, which is distinct from previously reported AR CL.

\section{CASE REPORT}

Patient 1, a girl, was the fourth child of first cousin healthy Tunisian parents (fig 1). The pregnancy was uneventful. Moderate hypotonia and cutis laxa were noted in the neonatal period (birth length $44 \mathrm{~cm},-2.5 \mathrm{SD}$; weight $2520 \mathrm{~g},-2 \mathrm{SD}$; OFC $34 \mathrm{~cm}$, mean). Clinical examination showed cleft hard palate, increased joint laxity, facial dysmorphism including square and flat face, high and broad forehead, very short nose, blue sclerae, sagging cheeks, and small mouth and chin. Palms and soles were normal. The patient could sit unaided aged 1 year and walk at 2.5 years. At 7 years of age she had mildly delayed growth development $(-1 \mathrm{SD})$, and mental retardation requiring special schooling. Cutis laxa improved with age and facial dysmorphism became more pronounced, with a round flat face, very short nose, blue sclerae, and small mouth (fig 1). Drooping cheeks disappeared with age and joint laxity was noted. Thoracic $x$ ray revealed slight pulmonary emphysema.

Patient 2, a boy, was the fifth child from the same sibship (fig 2). Prenatal hygroma and a moderate hydramnios were noted at 19 weeks of gestation. He was small for his age (length $46 \mathrm{~cm},-2 \mathrm{SD}$; weight $3000 \mathrm{~g},-1 \mathrm{SD}$; OFC $35 \mathrm{~cm}$,

\section{Key points}

- Cutis laxa $(\mathrm{CL})$ is a clinically and genetically heterogeneous condition characterised by loose and redundant skin with lack of elasticity.

- $\mathrm{CL}$ was found to be associated with facial dysmorphism, cleft palate, and moderate mental retardation in three siblings, born to first cousin healthy parents. Facial dysmorphism included flat and square face, very short nose, sagging cheeks, blue sclerae, hypertelorism, and small chin.

- Additional features included hygroma during pregnancy $(2 / 3)$, cleft hard palate (2/3), and ventricular septal defect (2/3). Skin histology showed a lack of elastic fibres (1/3). X ray and ophthalmological examinations were normal.

- The clinical features observed in our patients are compared with those described in other CL syndromes in the literature. Cleft palate, facial dysmorphism, joint laxity, mental retardation, and emphysema have not been previously reported in association with $\mathrm{CL}$.

- It is concluded, therefore, that this distinctive association represents a novel syndromic form of CL.

mean). Severe hypotonia, increased joint laxity, broad hands and feet, wide anterior fontanelle, and cutis laxa were noted in the neonatal period. Left hip dislocation and ulnar deviation of hands were also noted. His facial dysmorphism was similar to that of his sister, including square and flat face, high and broad forehead, very short nose, sagging cheeks, small chin, and normal palate. Excess of skin was noted on the neck, occiput, and limbs (fig 2). Examination of palms and soles was unremarkable. He died 25 days postpartum of severe emphysema and multiple pneumothorax. The family refused postmortem examination.

Patient 3, a girl, was the seventh child of the sibship (fig 3). Hygroma and hydramnios were detected at 14 weeks of gestation. She was born at term with severe hypotonia, increased joint laxity, complete Pierre-Robin sequence, and cutis laxa. Her length was $49 \mathrm{~cm}$, mean; weight $2990 \mathrm{~g}$, $-1 \mathrm{SD}$; and OFC $35 \mathrm{~cm},+1 \mathrm{SD}$ ). Facial features were similar to those of her affected sibs, namely square and flat face, high and broad forehead, very short nose with anteverted nostrils, small mouth and chin, cleft hard palate, hypertelorism, blue sclerae, and sagging cheeks (fig 3). She had an excess of skin on her neck, forehead, and abdomen, but palms and soles were normal. Tracheotomy was performed for respiratory distress. At 10 months of age she could not sit unaided, and 

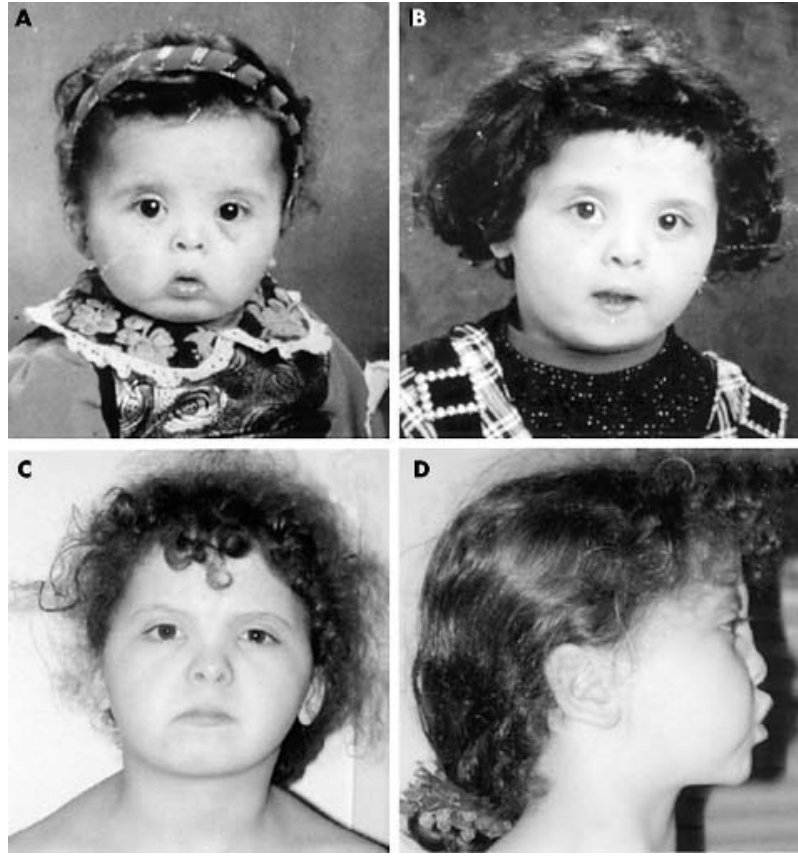

Figure 1 Facial features in patient 1 at 2 years (A) and 4 years (B) of age. Note the facial dysmorphism including square face, high and broad forehead, sagging cheeks, and small nose, chin, and mouth. At 7 years of age $(C, D)$, note round and flat face with posteriorly rotated ears.

she had severe hypotonia and developmental delay (growth and length $=-2 \mathrm{SD}, \mathrm{OFC}=+2 \mathrm{SD}$ ). She died at 10 months of age from progressive emphysema complicated by a pulmonary infection.

\section{METHODS}

With the written consent of the parents genomic DNA was purified from peripheral blood leucocytes according to standard techniques, ${ }^{13}$ and microsatellite markers of the Genethon map (http://www.genethon.fr/) were PCR amplified $^{14}$ and analysed on $6 \%$ polyacrylamide denaturing gel. To test linkage to the elastin gene, ${ }^{2}$ microsatellite DNA markers of chromosome 7q11.2 were used (D7S2472, D7S1870, D7S2470, D7S669, ELN, D7S524, D7S630, and D7S657). Microsatellite markers were also used to test linkage to the lysyl oxidase gene ${ }^{10}$ at chromosome 5q23.3-q31.2 (D5S433, D5S2027, D5S2055, D5S471, LOX, D5S2057, and D5S2115). Linkage to fibulin $5^{6}$ was tested using an intragenic microsatellite DNA marker (FBLN 5' GGT ACA ATG AGC TGA GAT CGT G, FBLN 3' ACT CAA CTC TCG GCT TGG TTA G).
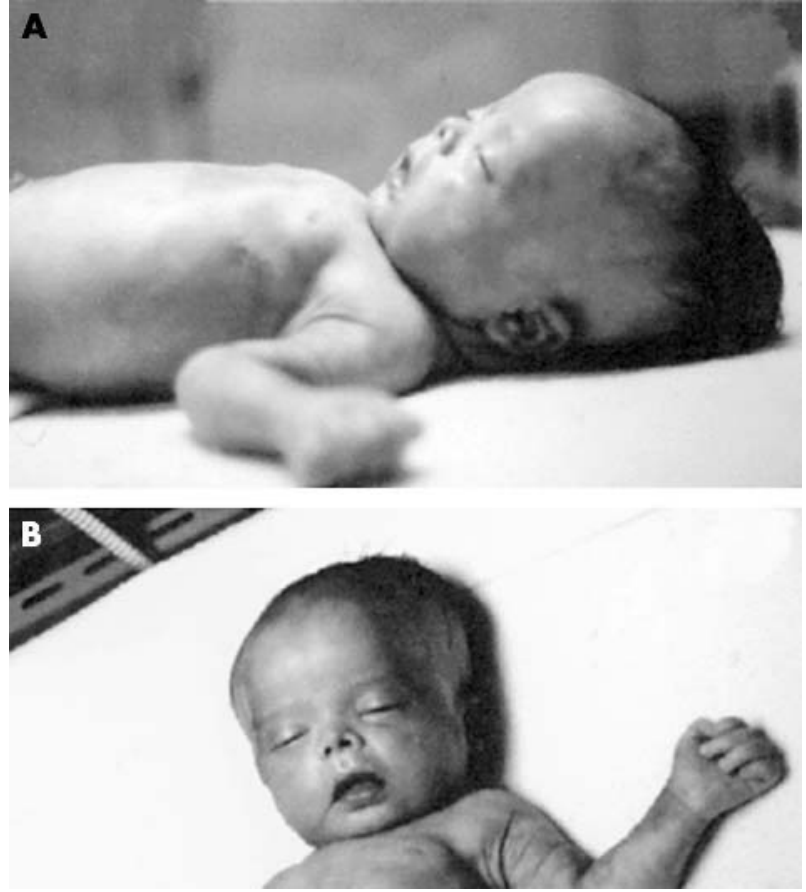

Figure 2 Facial features in patient 2 at day 25 ( $A$ and $B$ ). Note square and flat face, high and broad forehead, short nose, small chin, small mouth, and excess of skin on arms, neck, and occiput.

To test linkage to the COL2Al gene, we used polymorphic DNA markers of chromosome 12q13.11-q13.2 (D12S345, D12S85, COL2A1, D12S368, D12S83 and D12S1703).

\section{RESULTS}

\section{Laboratory investigations}

Cerebral MRI was normal in patient 1. In patient 3, cerebral CT showed cerebral atrophy, and thoracic CT showed diffuse pulmonary emphysema. Heart ultrasound showed a ventricular septal defect in $2 / 3$ patients. Skeletal $x$ rays showed advanced bone age (2/3) and a butterfly shaped hemivertebra in patient 2. Histological study of skin biopsy performed for patient 2 showed paucity of pre-elastic fibres and lack of mature elastic fibres (fig 4). Kidney ultrasound, ophthalmological examination, and high resolution blood chromosomes (including 22ql1.2 in situ hybridisation), amino acid, and organic acid chromatography were normal in all three cases. Copper metabolism was also normal in case 3 .
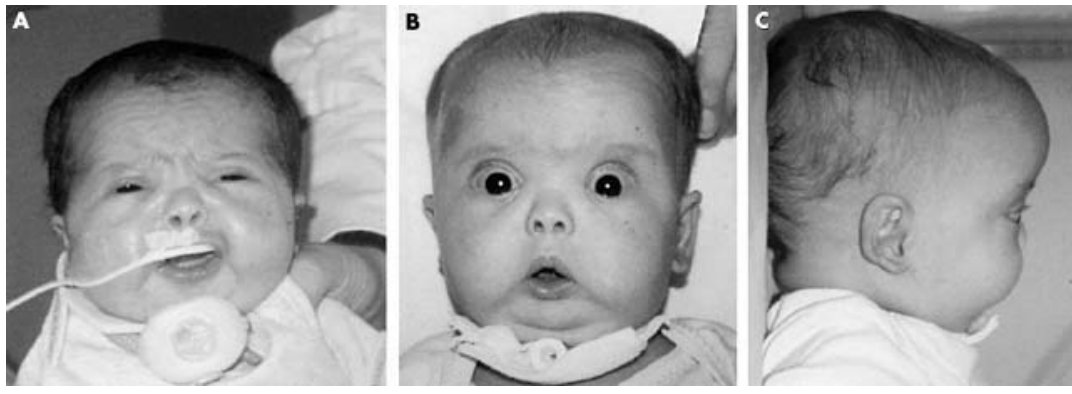

Figure 3 Facial features in patient 3 at day $4(A)$ and 2 months of age (B and $C)$. Note facial dysmorphism including square and flat face, high and broad forehead, hypertelorism, blue sclerae, sagging cheeks, small nose with anteverted nares, excess of skin, and small mouth with small chin. 

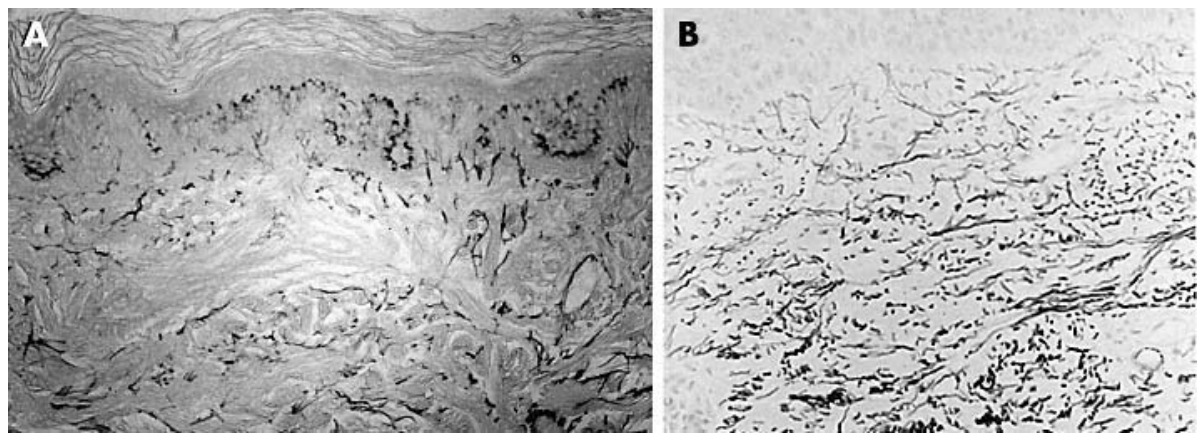

Figure 4 (A) Skin biopsy of patient 2 at 23 days old. (Catechin-fuchsin staining, magnification $\times 52$ ). The pre-elastic fibres (oxytalan + elaunin) in the superficial dermis are rarefied, and the elastic fibres are almost completely absent in the centre part of the dermis. (B) Skin biopsy of a control subject at 3 months of age (Catechin-fuchsin staining, magnification $\times 64$ ). Pre-elastic fibres (oxytalan + elaunin) are well defined in the superficial dermis and well structured with typical arborisation. Dermal elastic fibres are numerous and well positioned.

\section{Molecular studies}

In view of recent evidence for the involvement of elastin, ${ }^{2}$ lysyl oxydase, ${ }^{10}$ and fibulin $5^{6}$ in AR CL, we first tested these candidate genes by linkage analysis in affected children using flanking or intragenic microsatellites. Haplotype construction and segregation analyses excluded linkage to the elastin gene (fig 5), fibulin 5, lysyl oxidase, or COL2Al genes (data not shown).

\section{DISCUSSION}

This study reports on three sibs with a novel form of syndromic cutis laxa with facial dysmorphism, cleft hard palate, and mental retardation. The observation of CL in three sibs born to first cousin parents supports an AR mode of inheritance in this family. Molecular studies excluded the three genes known to be involved in CL, namely the elastin, lysyl oxidase, and fibulin 5 genes. Cleft hard palate and facial dysmorphism (square and flat face, short nose, small mouth and chin, and blue sclerae) have not been described before in any other AR CL syndrome. Table l compares the clinical findings in our patients with those of other AR CL syndromes which do not, in our opinion, account for the features observed in our family. Type I cutis laxa is characterised by emphysema, multiple pneumothorax, diverticulae, and hernias ${ }^{15}$; emphysema and multiple pneumothorax were indeed observed in $2 / 3$ of our cases, but their other features, namely cleft palate, mental retardation, and facial dysmorphism, have not been reported in type I CL, and involvement of fibulin 5 gene could be excluded.

De Barsy syndrome, combining mental retardation and increased joint laxity, could also be considered, but the absence of corneal clouding rules out this diagnosis. ${ }^{12}$ In fact, the cases in the present report share several clinical features

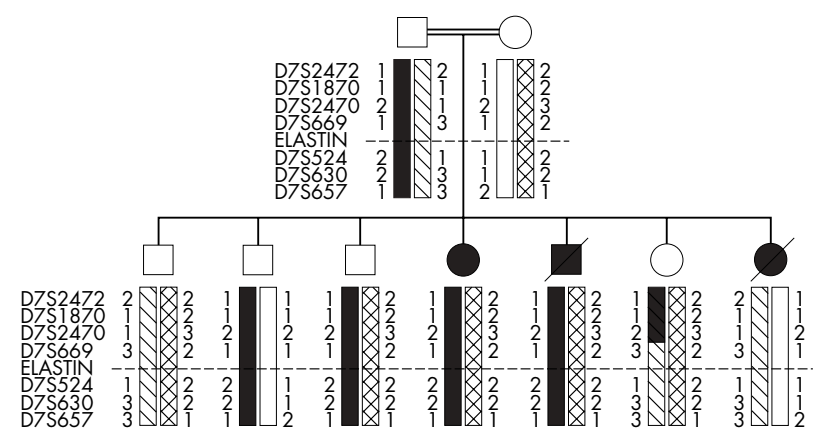

Figure 5 Linkage analysis using microsatellites markers at locus $7 q 11.2$ (elastin).
Table 1 Features observed in our cases in comparison with other autosomal recessive cutis laxa syndromes

\begin{tabular}{|c|c|c|c|c|c|c|}
\hline \multirow[b]{2}{*}{ Clinical features } & \multicolumn{3}{|c|}{ Present cases } & \multirow[b]{2}{*}{ CLI } & \multirow[b]{2}{*}{ CL II } & \multirow[b]{2}{*}{ DB } \\
\hline & Case 1 & Case 2 & Case 3 & & & \\
\hline $\begin{array}{l}\text { Hygroma/ } \\
\text { hydramnios }\end{array}$ & ? & $\begin{array}{l}+(19 \\
\text { WG) }\end{array}$ & $\begin{array}{l}+(14 \\
W G)\end{array}$ & - & - & - \\
\hline Neonatal hypotonia & + & + & + & + & + & + \\
\hline Cutis laxa & + & + & + & + & + & + \\
\hline Increased joint laxity & + & + & + & + & + & + \\
\hline $\begin{array}{l}\text { Wide anterior } \\
\text { fontanelle }\end{array}$ & - & + & + & + & + & - \\
\hline Mental retardation & + & NA & + & - & + & + \\
\hline Square and flat face & + & + & + & - & - & - \\
\hline Very short nose & + & + & + & - & - & - \\
\hline Blue sclerae & + & - & + & - & - & - \\
\hline Sagging cheeks & + & + & + & + & + & + \\
\hline $\begin{array}{l}\mathrm{PR} / \text { cleff hard } \\
\text { palate/small chin }\end{array}$ & + & + & + & - & - & - \\
\hline $\begin{array}{l}\text { Diverticulae and } \\
\text { hernias }\end{array}$ & - & - & - & + & - & + \\
\hline $\begin{array}{l}\text { Prenatal growth } \\
\text { deficiency }\end{array}$ & + & - & - & + & + & - \\
\hline $\begin{array}{l}\text { Postnatal growth } \\
\text { deficiency }\end{array}$ & - & - & - & + & - & + \\
\hline $\begin{array}{l}\text { Wrinkly skin on } \\
\text { palms and soles }\end{array}$ & - & - & - & - & + & - \\
\hline Corneal clouding & - & - & - & - & - & + \\
\hline Advanced bone age & + & - & + & - & - & - \\
\hline Emphysema & + & + & + & + & - & - \\
\hline $\begin{array}{l}\text { Ventricular septal } \\
\text { defect }\end{array}$ & + & - & + & - & - & - \\
\hline
\end{tabular}

CL, cutis laxa; DB, de Barsy syndrome; NA, not applicable; PR, PierreRobin sequence.

with AR CL type II ascribed to lysyl oxidase deficiency. However, the characteristic pre and postnatal growth retardation and loose skin on palms and soles were not present, and involvement of lysyl oxidase gene could be excluded in our family. ${ }^{16}$ The normality of palms and soles in our patients excludes wrinkly skin syndrome, which seems closely related (if not similar) to AR CL type II. ${ }^{11}$ Similarly, the association of Pierre-Robin sequence, with flat face, small chin, small nose, and prominent eyes, prompted us to test and eventually exclude COL2Al.

In conclusion, we suggest that the association of $\mathrm{CL}$, cleft hard palate, ventricular septal defect, and striking facial dysmorphism represents a novel form of autosomal recessive cutis laxa distinct from types I and II AR CL. Additional observations are needed to decide whether this association indeed represents a distinct and novel entity. 


\section{Authors' affiliations}

D Genevieve, C Huber, L Faivre, D Sanlaville, C Bodemer, S Hadj-

Rabia, F Raqbi, A Munnich, V Cormier-Daire, Département de

Génétique, Service de Dermatologie et de Pédiatrie Générale, Hôpital

Necker Enfants Malades, Paris, France

C Baumann, A Verloes, Service de Néonatologie, Hôpital Robert Debré,

Paris, France

A Assoumou, Laboratoire de Physiopathologie des Tissus non

Minéralisés, Faculté de Chirurgie Dentaire, Université René Descartes, Paris, France

Correspondence to: V Cormier-Daire, Hôpital Necker Enfants Malades, 149 rue de Sèvres 75743 Paris Cedex 15, France; cormier@necker.fr

\section{REFERENCES}

1 Beighton PH. The dominant and recessive forms of Cutis Laxa. J Med Genet 1972:9:216-21

2 Tassabehii M, Metcalfe K, Hurst J, Ashcroft GS, Kielty C, Wilmot C, Donnai D, Read $A P$, Jones $C J$. An elastin gene mutation producing abnormal tropoelastin and abnormal elastic fibres in a patient with autosomal dominant cutis laxa. Hum Mol Genet 1998:7:1021-8.

3 Byers PH, Narayanan AS, Bornstein P, Hall JG. An X-linked form of Cutis Laxa due to deficiency of lysyloxidase. Birth Defects: Original Article Series, 1976; 12:293-8.

4 Kaler SG, Gallo LK, Proud VK, Percy AK, Mark Y, Segal NA, Goldstein DS, Holmes CS, Gahl WA. Occipital horn syndrome and a mild Menkes phenotype associated with splice site mutations at the MNK locus. Nat Genet 1994;8:195-202.
5 Reisner SH, Seelenfreund M, Ben-Bassat M. Cutis laxa associated with severe intrauterine growth retardation and congenital dislocation of the hip. Acta Paediatr 1971;60:357-60

6 Loeys B, Van Maldergem L, Mortier G, Coucke P, Gerniers S Naeyaert JM, De Paepe A. Homozygosity for a missense mutation in Fibuline-5 (FBLN5) results in a severe form of cutis laxa. Hum Mol Genet 2002;11:2113-18.

7 Agha A, Sakati NO, Higginbottom MC, Jones KL, Bay C, Nyhan WL. Two forms of Cutis Laxa presenting in the newborn period. Acta Paediatr 1978:67:775-80

8 Kaye Cl, Fisher DE, Esterly NB. Cutis laxa, skeletal anomalies, and ambiguous genitalia. American Journal of Disease in Childhood, 1974;127:115-17.

9 Sakati NO, Nyhan WL, Shear CS, Kattan H, Akhtar M, Bay C, Jones KL, Schackner L. Syndrome of cutis laxa, ligamentous laxity, and delayed development. Pediatrics 1983;72:850-6.

10 Khakoo A, Thomas R, Trompeter R, Duffy P, Price R, Pope FM. Congenital Cutis Laxa and lysyl oxidase deficiency. Clin Genet 1997;51:109-14.

11 Zlotogora J. Wrinkly skin syndrome and the syndrome of cutis laxa with growth and developmental delay represent the same disorder. Am J Med Genet 1999:85:194.

12 De Barsy AM, Moens E, Dierckx L. Dwarfism, oligophrenia and degeneration of the elastic tissue in skin and cornea. A new syndrome? Helvetica Paediatrica Acta 1968;23:305-13.

13 Sambrook J, Fritsch EF, Maniatis T. Molecular cloning: a laboratory manual. 2nd ed. New York: Cold Spring Harbor Laboratory Press, 1989.

14 Mullis K, Faloona F, Scharf S, Saiki R, Horn G, Erlich H. Specific enzymatic amplification of DNA in vitro: the polymerase chain reaction. Biotechnology 1992:24:17-27.

15 Fitzsimmons JS, Fitzsimmons EM, Guibert PR, Zaldua V, Dodd KL. Variable clinical presentation of Cutis Laxa. Clin Genet 1985;28:284-95

16 Patton MA, Tolmie J, Ruthnum P, Bamforth S, Baraitser M, Pembrey M Congenital cutis laxa with retardation of growth and development. J Med Genet 1987;24:556-61. 